\title{
Corrections to 'The use of sterilised polyester mosquito net mesh for inguinal hernia repair in Ghana'
}

\author{
S. D. Shillcutt
}

Received: 26 August 2009 / Accepted: 18 September 2009 / Published online: 7 October 2009

(C) Springer-Verlag 2009

\section{Dear Editors,}

Calculations related to cost-effectiveness included in the paper by Clarke et al. [1] were drawn from a previous version of Shillcutt et al. [2], which contained several errors that should be highlighted. The correct values within the following sentence are in parentheses: "DALYs were calculated in the reference case, with an average of $18.90(9.32)$ DALYs averted per person, and a total of 2,136 $(1,052)$ DALYs averted in the study. Cost-effectiveness analyses identified an average cost of $\$ 636.65$ (\$120.02) per hernia repair from a provider perspective, with a resultant cost of $\$ 33.69$ (\$12.88) per DALY averted. Adjusting costs to the societal perspective resulted in an overall cost of $\$ 32.27$ (\$11.04) per DALY averted." Corrections and modifications made to the calculations included the following: provider costs were pro-rated to the length of the program, consistent with Gosselin et al. [3], instead of being simply annualized. Inflation to 2008 US\$ was previously done with Ghanaian inflation rates instead of US rates. Personnel costs collected on site were replaced with WHO-CHOICE figures to improve within-study consistency and acrossstudy comparability for decisions beyond the Ghanaian context. Transportation costs for European teams, costs of a 2-h radio campaign, eight water tanks to all hospitals, and multivitamin costs were added to augment the robustness of the costing. Corrections to DALY calculations were made in a previous erratum [4], which highlight the importance of using formulas directly from the Global Burden of Disease (GBD) website [5].

S. D. Shillcutt $(\varangle)$

Department of International Health,

Johns Hopkins Bloomberg School of Public Health,

615 N. Wolfe St., Baltimore, MD 21205, USA

e-mail: samuel.shillcutt@gmail.com
Our evidence is based on a small cohort study and there are several areas where it could be strengthened. Costs should be measured in similar settings to corroborate or challenge our findings. Empirically based disability weights should be defined to reflect true patient or provider preferences. The rationale behind our modeling of outcomes from longstanding hernias is based on the best available evidence and is open for debate. Testing the effectiveness and costeffectiveness of this kind of program on a larger scale would strengthen evidence for policy decisions. Monitoring these programs as they develop local self-sufficiency, as African health systems strengthen, and as the epidemiology of hernias evolve is an exciting area for future research.

\section{References}

1. Clarke MG, Oppong C, Simmermacher R et al (2009) The use of sterilised polyester mosquito net mesh for inguinal hernia repair in Ghana. Hernia 13:155-159

2. Shillcutt SD, Clarke MG, Kingsnorth AN (2009) Cost-effectiveness of groin hernia surgery in the western region of Ghana. Arch Surg (in press)

3. Gosselin RA, Thind A, Bellardinelli A (2006) Cost/DALY averted in a small hospital in Sierra Leone: what is the relative contribution of different services? World J Surg 30:505-511

4. Clarke MG, Oppong C, Simmermacher R et al (2009) Erratum: The use of sterilised polyester mosquito net mesh for inguinal hernia repair in Ghana. Hernia 13:341. doi:10.1007/s10029-009-0488-z

5. World Health Organization (2009) Health statistics and health information systems: national tools. WHO. Available online at: http:// www.who.int/healthinfo/global_burden_disease/tools_national/en/ index.html 